\title{
Travel burden and geographic access to health care among children with cancer in Saudi Arabia
}

Abdulrahman Alsultan,,${ }^{1,2}$ Abdullah Aljefri, ${ }^{3}$ Mouhab Ayas, ${ }^{3}$ Musa Alharbi, ${ }^{4}$ Nawaf Alkhayat, ${ }^{5}$ Faisal Al-Anzi, ${ }^{6}$ Fawwaz Yassin, ${ }^{7}$ Fawaz Alkasim, ${ }^{8}$ Qasim Alharbi, ${ }^{9}$ Shaker Abdullah, ${ }^{10}$ Mohammed Abrar ${ }^{10}$ and Wasil Jastaniah ${ }^{10,11}$

Department of Pediatrics, College of Medicine, King Saud University, Riyadh, Saudi Arabia (Correspondence to: A. Alsultan: aalsultanı@ksu.edu.sa). ${ }^{2}$ Department of Pediatric Hematology/Oncology, King Abdullah Specialist Children's Hospital, Riyadh, Saudi Arabia. ${ }^{3}$ Department of Pediatric Hematology/Oncology, King Faisal Specialist Hospital \& Research Center, Riyadh, Saudi Arabia. ${ }^{4}$ Department of Pediatric Hematology/Oncology, Cancer Center, King Fahad Medical City, Riyadh, Saudi Arabia. ${ }^{5}$ Department of Pediatrics, Prince Sultan Military Medical City, Riyadh, Saudi Arabia. ${ }^{6}$ Prince Faisal Bin Bandar Cancer Center, Qassim, Saudi Arabia. ${ }^{7}$ Department of Pediatric Hematology/Oncology, King Faisal Specialist Hospital \& Research Center, Jeddah, Saudi Arabia. ${ }^{8}$ Department of Pediatric Hematology and Oncology, King Saud Medical City, Riyadh, Saudi Arabia. ${ }^{\circ}$ Department of Pediatric Hematology/Oncology, King Fahad Specialist Hospital, Dammam, Saudi Arabia. ${ }^{10}$ Department of Oncology, Princess Noorah Oncology Center, King Saud Bin Abdulaziz University and King Abdulaziz Medical City, Jeddah, Saudi Arabia. "'Department of Pediatrics, Faculty of Medicine, Umm Al-Qura University, Makkah, Saudi Arabia.

\begin{abstract}
Background: Travel burden has a substantial psychosocial impact and financial strain on childhood cancer patients and their families.

Aims: To study the geographic distribution of childhood cancer and assess the travel burden for care in Saudi Arabia.

Methods: This was a cross-sectional multi-institutional study that enrolled 1657 children with cancer who were diagnosed between 2011 and 2014. Cancer type/stage, city/region of residence, and city/region of treating centre were recorded. Travel burden was measured based on a 1-way distance in kilometres from the city centre to the treatment institution. This study was supported by Sanad Children's Cancer Support Association.

Results: Diagnosis was leukaemia (45.2\%), non-CNS solid tumours (30.2\%), lymphoma (12.3\%), CNS tumours (11.8\%) and histiocytosis (0.5\%). Childhood cancer centres were in the same city as where the patients lived in $652(39.3 \%)$ cases, same region but different city in $308(18.6 \%)$, different regions in $613(37 \%)$, and not known in $84(5.1 \%)$. The mean 1-way travel distance for patients who lived in different regions was 790 (range, 116-1542) km. A total of $536(32 \%)$ patients lived $\geq 400 \mathrm{~km}$ and $216(13 \%)>1000 \mathrm{~km}$ from the treatment centre. Among 642 patients with acute lymphoblastic leukaemia who required 2-3 years of therapy, $197(31 \%)$ lived $\geq 400 \mathrm{~km}$ and $94(15 \%)>1000 \mathrm{~km}$ from the treatment centre.
\end{abstract}

Conclusions: Nearly two thirds of patients with childhood cancer lived in different cities than the treatment centres, including one third of patients who lived $\geq 400 \mathrm{~km}$ away. There is a need to develop strategies to improve access to childhood cancer care.

Keywords: cancer, geographic distribution, paediatrics, Saudi Arabia, travel burden

Citation: Alsultan A; Aljefri A; Ayas M; Alharbi M; Alkhayat N; Al-Anzi F; et al. Travel burden and geographic access to health care among children with cancer in Saudi Arabia. East Mediterr Health J. 2020;26(11):1355-1362. https://doi.org/10.26719/emhj.20.020

Received: 10/04/19; accepted: 13/11/19

Copyright (C) World Health Organization (WHO) 2020. Open Access. Some rights reserved. This work is available under the CC BY-NC-SA 3.o IGO

license (https://creativecommons.org/licenses/by-nc-sa/3.o/igo)

\section{Introduction}

The outcome of childhood cancer has improved significantly in recent decades with current estimated 5-year survival rates of $80 \%$. This progress has been due to successful clinical trials conducted by collaborative research groups, such as the Children's Oncology Group, combined with advances in supportive care $(1,2)$. However, during progression to cure, other concerns might arise in families of children with cancer, such as employment disruption, high out-of-pocket spending, travel burden, and psychosocial difficulties $(3,4)$. These concerns are infrequently addressed in depth with families given that the focus of medical teams is primarily on delivering optimal treatment. Governmental financial support for patients and their families, active involvement of social service teams at cancer centres, and support from nonprofit organizations are ways to address some of these concerns in Saudi Arabia.
Childhood cancer in Saudi Arabia affects 1 in 10000 children. The 2015 Saudi Cancer Registry Report showed that leukaemia was the most common childhood cancer $(35 \%)$ followed by brain tumours $(12.2 \%)$ and non-Hodgkin's lymphoma (12.2\%) (5). Centres that treat childhood cancer are mainly in 4 (Riyadh, Makkah, Eastern and Qassim) out of the 13 regions in Saudi Arabia. Patients and their families in the remaining 9 regions need to travel long distances by land or air for their initial diagnosis and treatment. Increased travel distance between the residence of patients and the treatment centre is associated with increased financial burden, work interruption, and residence relocation (6). In a large study in the United Kingdom of Great Britain and Northern Ireland, travel burden was associated with survival disadvantage among cancer patients (7).

The travel burden and its impact on cancer outcome have not been studied in Saudi Arabia. In this study, 
we examined the geographic distribution of childhood cancer in different regions in Saudi Arabia, assessed the burden of travel among patients and their families, and evaluated the influence of travel burden on the initial cancer staging in solid tumours.

\section{Methods}

\section{Patient population}

We performed a cross-sectional multi-institutional study in 10 centres that treat most cases of childhood cancer in Saudi Arabia. Informed consent was obtained from parents of all participants and the study was approved by the institutional review boards in all participating institutions. We enrolled 1657 patients: 917 (55\%) male and 740 $(45 \%)$ female. aged $\leq 14$ years who were diagnosed with cancer between January 2011 and December 2014. We collected the following information: cancer type, cancer stage, city/region of residence, and city/region of treatment centre. Data were recorded remotely using REDCap (Research Electronic Data Capture) electronic data capture tools hosted and stored centrally in a secure Microsoft SQL database (8). The study was organized by the Saudi Arabian Pediatric Hematology Oncology Society (SAPHOS) as part of a study to determine the prevalence of hereditary cancer syndromes, as described previously (9). It was supported by Sanad Children's Cancer Support Association.

\section{Geographic distribution and travel burden of childhood cancer}

Number of patients, sex and characteristics of cancer were described for each region. The proportion of childhood cancer in each region was compared to the proportion of normal children aged $\leq 14$ years living in the same region, using data from the demographic survey performed in 2016 by the Saudi General Authority of Statistics (10). Travel burden was assessed using Google map based on a 1-way distance in kilometres from the city centre where the patients lived, to the treatment institution.

\section{Data analysis}

Descriptive analyses were presented as mean (standard deviation) values for continuous data and as frequencies for categorical data. At test was used to compare 2 means and $\chi^{2}$ or Fisher's exact test to compare proportions of 2 groups. Patients who lived in the same city as the treatment institution were used as a reference group. $P<0.05$ was considered to be statistically significant. Stata Statistical Software Release 12 was used for all analyses (StataCorp LP, College Station, TX, USA).

\section{Results}

\section{Cancer epidemiology in different regions}

Cancer classification and geographic distribution of patients who were enrolled in the study are summarized in Table 1. The total number of patients $(n=1657)$ enrolled in our study represented 50\% of all childhood cancer cases expected to be diagnosed during the study period, based on the Saudi Cancer Registry (5). A total of 1501 (91\%) patients were Saudi and the remaining $156(9 \%)$ were from other nationalities. Leukaemia was the most common diagnosis (45.2\%), followed by non-CNS solid tumours $(30.2 \%)$, lymphoma $(12.3 \%)$, CNS tumours $(11.8 \%)$ and lastly histiocytosis (0.5\%). There was no marked difference in the pattern of cancer among regions. Figure 1 shows the proportion of children with cancer in each region as well as the proportion of normal children aged $\leq 14$ years. The proportion of children with cancer who lived in Riyadh Region was $30.8 \%$ of all patients enrolled in our study, while the proportion of normal children who lived in Riyadh Region was $24.7 \%$ of all normal Saudi children $(P<$ $0.0001)$.

\section{Travel burden and access to cancer care in different regions}

Treatment institutions were in the same city for only $652(39.3 \%)$ patients (Table 2). The treatment centre was in the same region but different city for $308(18.6 \%)$ patients and the average 1-way travel distance among those patients was 159 (range, 19-737) km. The remaining 613 (37\%) patients lived in different regions from the treatment centres with a mean 1-way travel distance of 790 (range, 116-1542) km. A total of 536 (32\%) patients lived $\geq 400 \mathrm{~km}$ and $>3$ hours travel time from the treatment centres. Among those, $216(13 \%)$ patients lived $>1000 \mathrm{~km}$ from the treatment centre.

Patients with acute lymphoblastic leukaemia (ALL) required prolonged therapy and frequent visits to cancer centres for several years. There were 642 patients with ALL in our study: 283 (44\%) lived in the same city as the treatment centre; $103(16 \%)$ lived in the same region but different city; $230(36 \%)$ lived in a different region; and the address was unknown for $26(4 \%)$. The average travel distance for ALL patients who lived in different regions was 792 (range, 280-1542) km. A total of 197 (31\%) ALL patients lived $\geq 400 \mathrm{~km}$ from the treatment centre, and $94(15 \%)$ of those lived $>1000 \mathrm{~km}$ distant.

\section{Regional referral pattern in childhood cancer}

Most patients living in Riyadh (99\%), Makkah (90\%) and Qassim (90\%) Regions were treated in the same region. Nearly half of patients living in the Eastern Region (45\%) had to be treated in Riyadh. Childhood cancer centres in Riyadh were the main referral centres for most regions, except Madinah and Albaha, and centres in Jeddah treated most patients from these 2 regions (Table 3, Figure 2). There were 613 patients who lived in different regions than the cancer centres: $453(74 \%)$ were treated in Riyadh, $139(23 \%)$ in Jeddah and 21 (3\%) in Qassim.

\section{Discussion}

In this study, we described the geographic distribution of childhood cancer and assessed the travel burden among our patients and their families. Nearly two thirds of 


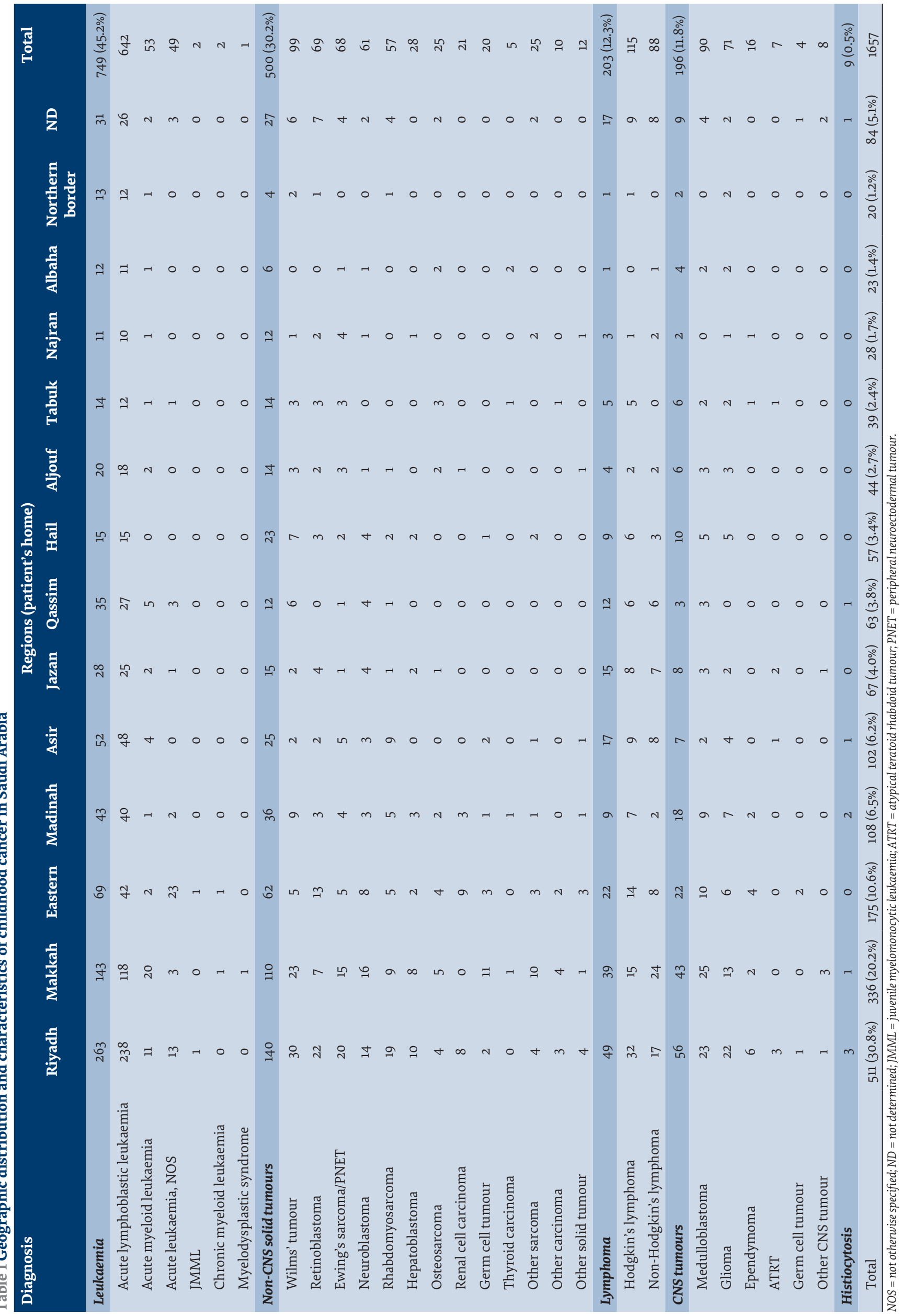


Figure 1 Regional distribution of childhood cancer in Saudi Arabia. Proportion of childhood cancer $(C)$ in each region in relation to the total number of childhood cancer cases $(n=$ 1657) is shown. Proportion of normal children aged $\leq 14$ years (N) in each region in relation to the total number of normal children aged $\leq 14$ years in Saudi Arabia $(n=7864$ 928) is also shown.

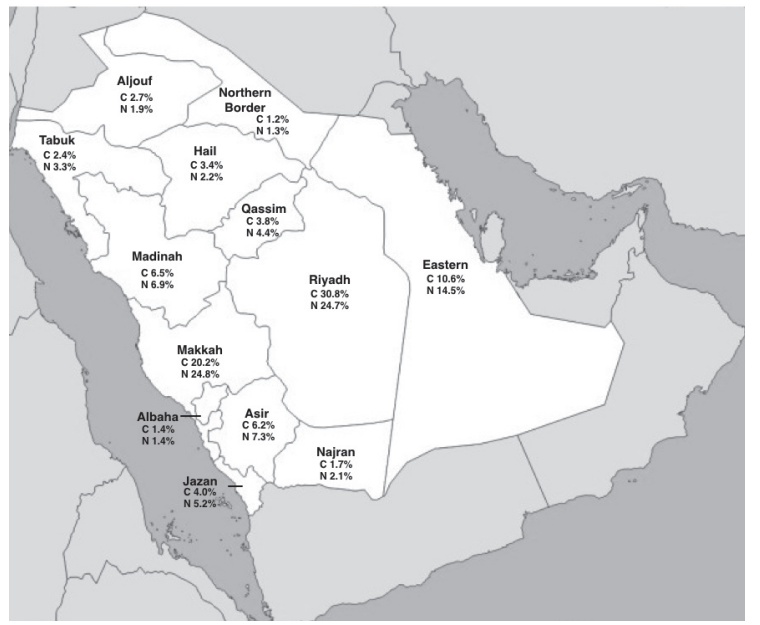

patients lived in cities other than the city of the treatment centre, including one third of patients who lived in different regions. The average travel burden was 1-way travel of $790 \mathrm{~km}$ for patients living in different regions than the treatment centres. There was a higher proportion of childhood cancer patients who lived in Riyadh Region (30.8\%) compared to $24.7 \%$ of normal children living in the region. This was probably caused by residence relocation to Riyadh by some families to be closer to cancer treatment centres. The government covers the cost of airline tickets for patients and their parents; however, on many occasions families need to drive long distances because of fully booked flights. Additionally, the travel burden is exacerbated by the limited accessibility to assigned local primary care physicians that is a common practice in Saudi Arabia. Thus, most of our patients' health care is provided at cancer centres.

Travel burden has multiple negative effects on cancer patients and their families. One study showed that childhood cancer patients living in rural areas were at higher risk of missing more school days, and their caregivers missed more work days and spent more outof-pocket travel expenses compared to urban residents (6). Travel burden was highest for patients living in rural areas in Australia and was associated with significant financial strains (11). For colon cancer patients in the United States of America (USA), increased travel distance to cancer centres was associated with advanced stage at diagnosis and lower possibility of receiving adjuvant chemotherapy within 90 days of colectomy $(12,13)$.
Treatment outcome and survival were not assessed in our study. Thus, it is possible that patients living in remote areas might have worse outcome due to delay in managing cancer or treatment-related complications such as febrile neutropenia. Nevertheless, there is probably a survival advantage for patients traveling to more experienced childhood cancer centres in Saudi Arabia. This is supported by the survival benefit that was observed in the USA among cancer patients receiving treatment at National Cancer Institute (NCI)-designated cancer centres (14). Establishing satellite facilities of the main NCI cancer centres has improved geographic access to high-quality cancer care, with nearly $85 \%$ of the American population living within 3 hours of either a parent or satellite facility (15). There are currently limited numbers of satellite facilities that are administered by large childhood cancer centres in Saudi Arabia. Therefore, establishing satellite facilities or affiliated medical centres should be a priority to improve geographic access to cancer care among Saudi patients. In addition, incorporating survival data in the current Saudi Cancer Registry is essential.

There is a need to develop strategies to improve access to cancer care in Saudi Arabia. Formation of a national referral system to coordinate between different healthcare sectors will facilitate timely access to childhood cancer centres. The integration of local primary care physicians (PCPs) in the care of children with cancer is essential (16). Paediatric oncologists should encourage parents to have local PCPs for their children. Additionally, there is a need to conduct regular workshops to train local PCPs and other local healthcare providers on various topics in childhood cancer, to enable them to recognize cancer at an early stage, refer patients promptly to cancer centres, and provide appropriate management of potential complications (17). It is also

\begin{tabular}{lc}
\hline $\begin{array}{l}\text { Table } 2 \text { Travel burden among children with cancer and their } \\
\text { families }\end{array}$ \\
\begin{tabular}{lc}
\hline Locations of treatment centre & No. of patients (\%) \\
\hline Same city & $652(39.3 \%)$ \\
Same region but different city & $308(18.6 \%)$ \\
Different region & $613(37.0 \%)$ \\
$<200 \mathrm{~km}$ & $3(0.1 \%)$ \\
$200-<400 \mathrm{~km}$ & $74(4.5 \%)$ \\
$400-<600 \mathrm{~km}$ & $122(7.4 \%)$ \\
$600-<800 \mathrm{~km}$ & $104(6.3 \%)$ \\
$800-<1000 \mathrm{~km}$ & $94(5.7 \%)$ \\
$1000-<1200 \mathrm{~km}$ & $124(7.5 \%)$ \\
$1200-<1400 \mathrm{~km}$ & $89(5.4 \%)$ \\
$1400-<1600 \mathrm{~km}$ & $3(0.1 \%)$ \\
Unknown & $84(5.1 \%)$ \\
\hline
\end{tabular}
\end{tabular}

Distance is based on 1-way travel. 


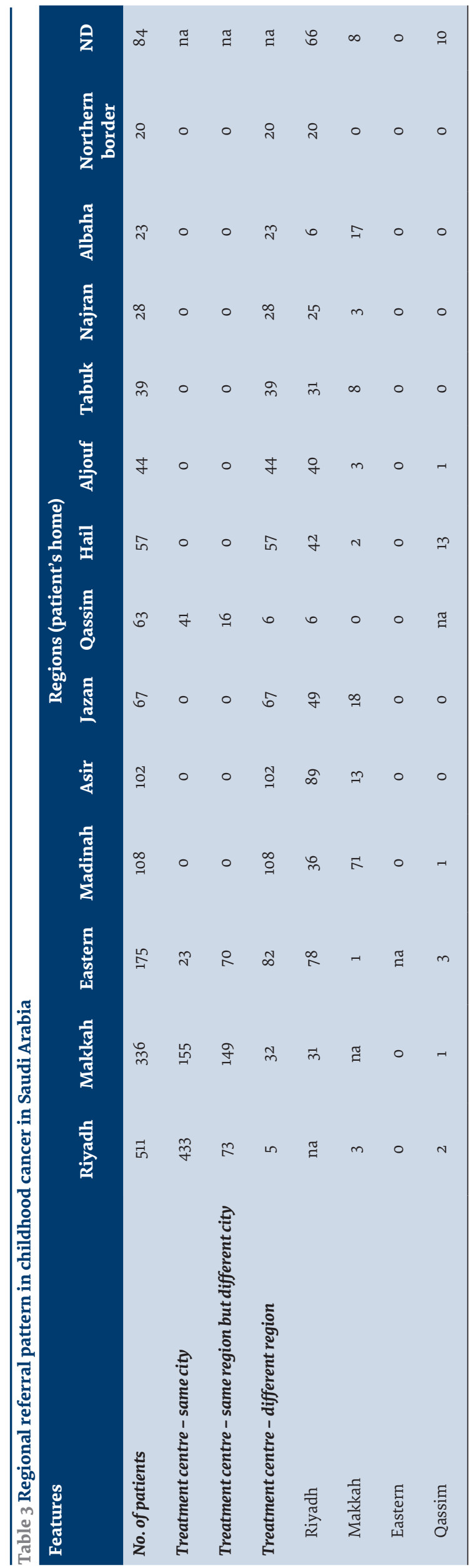

important to involve PCPs in the long-term care of cancer survivors (18). Availability of 24-hour helpline at childhood cancer centres is necessary to support PCPs and give caregivers direct communication with oncologists at any time. Travel and accommodation support should be integrated into the cancer care of children in Saudi Arabia.

Our study was limited by the lack of data on the date of first appearance of symptoms and signs of cancer compared to dates of diagnosis and starting treatment in order to measure accurately the impact of travel burden on the time to initiate cancer treatment. There are inconsistent reports on the association between time to diagnosis or treatment and poor survival in childhood cancer $(19,20)$. Another study limitation was enrolling only patients who were treated at cancer centres. Thus, we could not assess potential early mortality among children with cancer living in rural areas prior to their acceptance in cancer centres. Early death within the first month of diagnosis in childhood cancer was associated with age $<1$ year, low socioeconomic status, and certain cancers such as acute myeloid leukaemia (21).

\section{Conclusion}

The travel burden on children with cancer and their families in Saudi Arabia is substantial. Approximately two thirds of patients live in cities different from where the cancer centres are located. One third of patients are $>3$ hours away $(\geq 400 \mathrm{~km}$ ) from cancer centres. Our findings might guide policy-makers to develop national strategies to improve access to childhood cancer care in Saudi Arabia. Future studies are needed to assess the impact of living remotely from cancer centres on different outcomes such as event-free and overall survival.

Funding: The study was funded by Sanad Children's Cancer Support Association Research Grant Programme.

Competing interests: None declared.

Figure 2 Regional referral pattern of childhood cancer in Saudi Arabia. Childhood cancer centres are present in 4 circled cities. Arrows represent common referral patterns from each region. The weight of the arrow corresponds to the proportion of patients referred to a specific region.

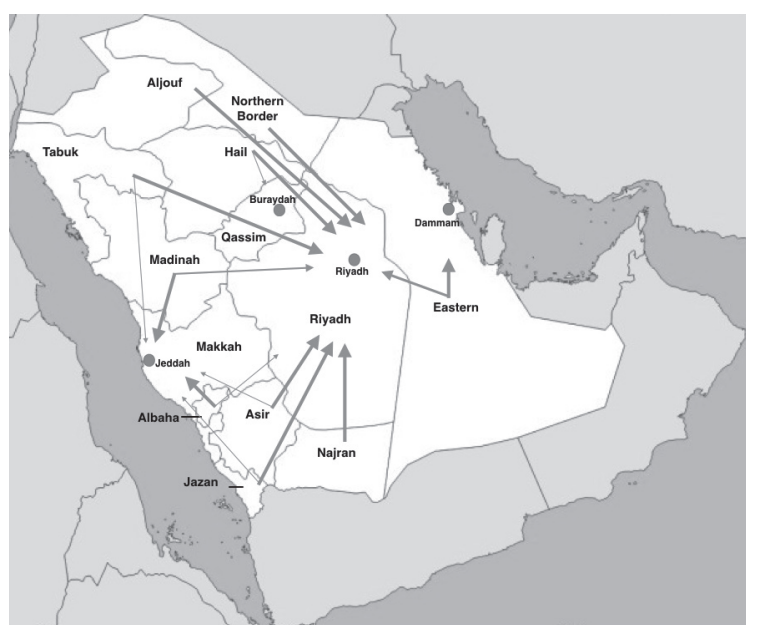




\section{Poids des déplacements et accès géographique aux soins de santé pour les enfants atteints de cancer en Arabie saoudite}

\section{Résumé}

Contexte : Le poids des déplacements a un impact psychosocial et financier considérable sur les enfants atteints de cancer et sur leurs familles.

Objectifs : La présente étude avait pour objectif d'étudier la répartition géographique du cancer chez l'enfant et d'évaluer le poids des déplacements pour les soins en Arabie saoudite.

Méthodes: Il s'agissait d'une étude transversale multi-institutionnelle portant sur 1657 enfants atteints de cancer, diagnostiqués entre 2011 et 2014. Le type/stade du cancer, la ville/région de résidence et la ville/région du centre de traitement ont été enregistrés. Le poids des déplacements a été mesuré sur la base de la distance en kilomètres, dans un sens, entre le centre de la localité et l'établissement de soins. Cette étude a reçu le soutien de Sanad Children's Cancer Support Association.

Résultats : Les diagnostics concernaient la leucémie (45,2\%), les tumeurs solides hors système nerveux central (30,2\%), le lymphome ( $12,3 \%)$, les tumeurs du système nerveux central ( $11,8 \%$ ) et l'histiocytose $(0,5 \%)$. Les centres de lutte contre le cancer de l'enfant se trouvaient dans la même ville que celle où les patients vivaient dans 652 cas (39,3\%), dans la même région, mais dans des villes différentes dans 308 cas (18,6\%) et dans des régions différentes dans 613 cas (37\%). Ce lieu n'était pas connu dans 84 cas $(5,1 \%)$. La distance moyenne parcourue par trajet pour les patients qui vivaient dans des régions différentes était de $790 \mathrm{~km}$ (distance comprise entre 116 et $1542 \mathrm{~km}$ ). Au total, 536 patients (32\%) vivaient à $400 \mathrm{~km} \mathrm{du}$ centre de traitement et $216(13 \%)$ à plus de $1000 \mathrm{~km}$. Parmi les 642 patients atteints de leucémie lymphoblastique aiguë ayant nécessité deux à trois ans de traitement, 197 (31\%) vivaient à une distance supérieure ou égale à $400 \mathrm{~km}$ du centre de traitement et $94(15 \%)$ à plus de $1000 \mathrm{~km}$.

Conclusions : Près des deux tiers des patients atteints d'un cancer de l'enfant vivaient dans des villes différentes des centres de traitement, dont un tiers des patients à une distance supérieure ou égale à $400 \mathrm{~km}$. Il est nécessaire d'élaborer des stratégies visant à améliorer l'accès aux soins des enfants atteints de cancer.

\section{عبء السفر وإتاحة الرعاية الصحية بالمناطق الجغر افية التي يعيش فيها الأطفال المصابون بالسرطان في المملكة العربية السعودية} عبد الرحمن السلطان، عبد الله الجفري، مهاب إياس، موسى الحربي، نو اف الخياط، فيصل العنزي، فواز ياسين، فواز القاسم، قاسم الحربي، شاكر

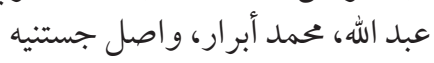

$$
\text { الخلفية: يؤثر عبء السفر تأثيراً نفسياً واجتماعياً كبيراً، ويفرض ضغوطاً مالية على مرضى سرطان الأطفال وأُسرهم. }
$$

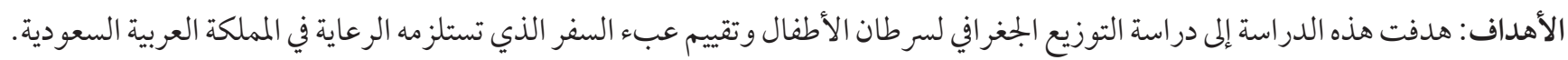

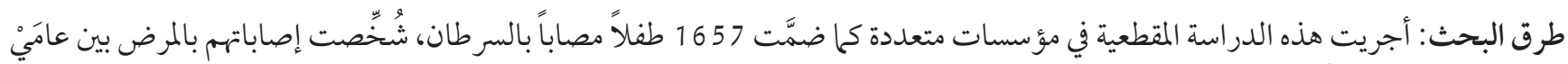

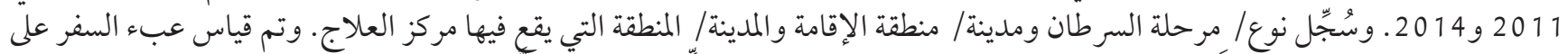

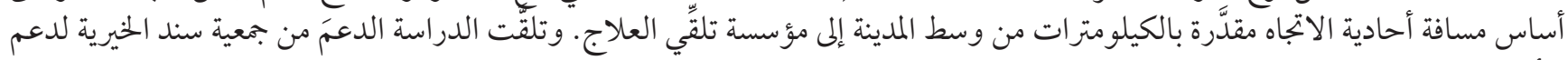
الأطفال المرضى بالسرطان.

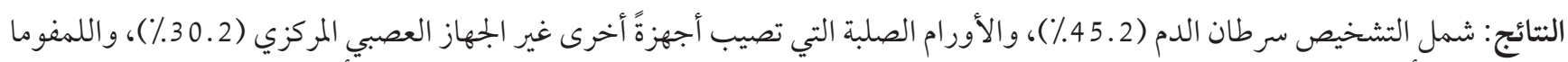

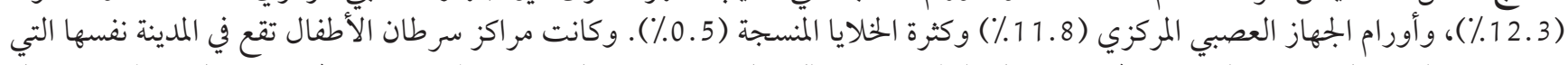

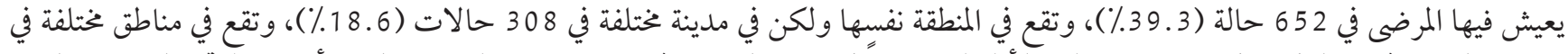

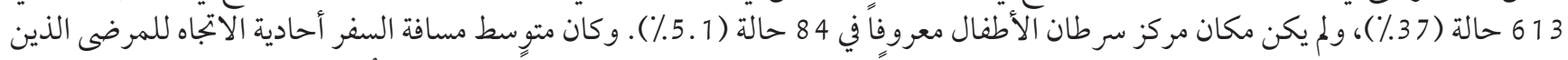

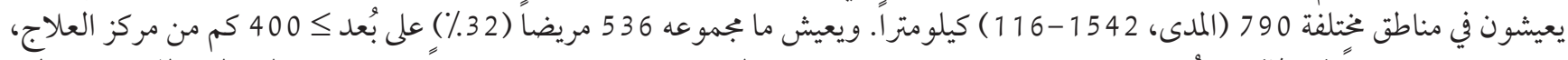

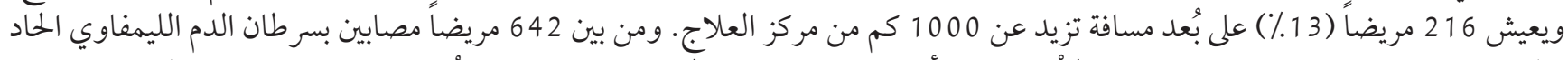

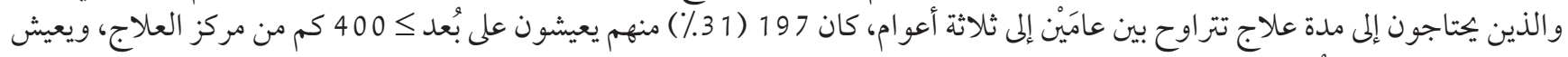
94

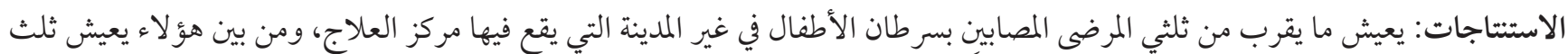

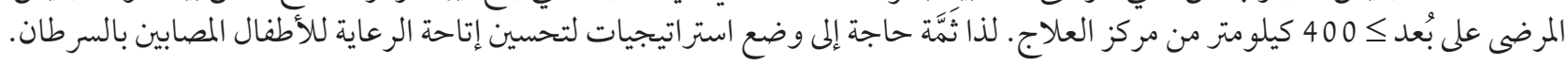




\section{References}

1. Siegel RL, Miller KD, Jemal A. Cancer Statistics, 2017. CA Cancer J Clin. 2017 Jan;67(1):7-30. http://dx.doi.org/10.3322/caac.21387 PMID:28055103

2. Adamson PC. Improving the outcome for children with cancer: development of targeted new agents. CA Cancer J Clin. 2015 May-Jun;65(3):212-20. http://dx.doi.org/10.3322/caac.21273 PMID:25754421

3. Steele AC, Mullins LL, Mullins AJ, Muriel AC. Psychosocial interventions and therapeutic support as a standard of care in pediatric oncology. Pediatr Blood Cancer. 2015 Dec;62 Suppl 5:S585-618. http://dx.doi.org/10.1002/pbc.25701 PMID:26700919

4. Nipp RD, Kirchhoff AC, Fair D, Rabin J, Hyland KA, Kuhlthau K, et al. Financial burden in survivors of childhood cancer: a report from the Childhood Cancer Survivor Study. J Clin Oncol. 2017 Oct 20;35(30):3474-81. http://dx.doi.org/10.1200/JCO.2016.71.7066 PMID:28817372

5. Saudi Health Council, National Health Information Center, Saudi Cancer Registry. Cancer incidence report Saudi Arabia 2015 (https://nhic.gov.sa/eServices/Documents/E\%20SCR\%20final\%206\%20NOV.pdf, accessed 17 April 2020).

6. Fluchel MN, Kirchhoff AC, Bodson J, Sweeney C, Edwards SL, Ding Q, et al. Geography and the burden of care in pediatric cancers. Pediatr Blood Cancer. 2014 Nov;61(11):1918-24. http://dx.doi.org/10.1002/pbc.25170 PMID:25131518

7. Turner M, Fielding S, Ong Y, Dibben C, Feng Z, Brewster DH, et al. A cancer geography paradox? Poorer cancer outcomes with longer travelling times to healthcare facilities despite prompter diagnosis and treatment: a data-linkage study. Br J Cancer. 2017;117(3):439-49. https://doi.org/10.1038/bjc.2017.180

8. Harris PA, Taylor R, Thielke R, Payne J, Gonzalez N, Conde JG. Research electronic data capture (REDCap) - a metadata-driven methodology and workflow process for providing translational research informatics support. J Biomed Inform. 2009 Apr;42(2):377-81. http://dx.doi.org/10.1016/j.jbi.2008.08.010 PMID:18929686

9. Jastaniah W, Aljefri A, Ayas M, Alharbi M, Alkhayat N, Al-Anzi F, et al. Prevalence of hereditary cancer susceptibility syndromes in children with cancer in a highly consanguineous population. Cancer Epidemiol. 2018 Aug;55:88-95. http://dx.doi.org/10.1016/j. canep.2018.05.006 PMID:29859499

10. Demographic Survey 2016. General Authority for Statistics. https://www.stats.gov.sa/sites/default/files/en-demographic-re: search-2016_4.pdf, accessed 17 April 2020).

11. Zucca A, Boyes A, Newling G, Hall A, Girgis A. Travelling all over the countryside: travel-related burden and financial difficulties reported by cancer patients in New South Wales and Victoria. Aust J Rural Health. 2011 Dec;19(6):298-305. http://dx.doi. org/10.1111/j.1440-1584.2011.01232.x PMID:22098213

12. Lin CC, Bruinooge SS, Kirkwood MK, Olsen C, Jemal A, Bajorin D, et al. Association between geographic access to cancer care, insurance, and receipt of chemotherapy: geographic distribution of oncologists and travel distance. J Clin Oncol. 2015 Oct 1;33(28):3177-85. http://dx.doi.org/10.1200/JCO.2015.61.1558 PMID:26304878

13. Massarweh NN, Chiang YJ, Xing Y, Chang GJ, Haynes AB, You YN, et al. Association between travel distance and metastatic disease at diagnosis among patients with colon cancer. J Clin Oncol. 2014 Mar 20;32(9):942-8. http://dx.doi.org/10.1200/ JCO.2013.52.3845 PMID:24516014

14. Onega T, Duell EJ, Shi X, Demidenko E, Gottlieb D, Goodman DC. Influence of NCI cancer center attendance on mortality in lung, breast, colorectal, and prostate cancer patients. Med Care Res Rev. 2009 Oct;66(5):542-60. http://dx.doi. org/10.1177/1077558709335536 PMID:19454624

15. Onega T, Alford-Teaster J, Wang F. Population-based geographic access to parent and satellite National Cancer Institute Cancer Center facilities. Cancer. 2017 Sep 1;123(17):3305-11. http://dx.doi.org/10.1002/cncr.30727 PMID:28464212

16. Rubin G, Berendsen A, Crawford SM, Dommett R, Earle C, Emery J, et al. The expanding role of primary care in cancer control. Lancet Oncol. 2015 Sep;16(12):1231-72. http://dx.doi.org/10.1016/S1470-2045(15)00205-3 PMID:26431866

17. Radhi M, Fulbright JM, Ginn KF, Guest EM. Childhood cancer for the primary care physician. Prim Care. 2015 Mar;42(1):43-55. http://dx.doi.org/10.1016/j.pop.2014.09.006 PMID:25634704

18. Signorelli C, Wakefield CE, Fardell JE, Wallace WHB, Robertson EG, McLoone JK, et al. The impact of long-term follow-up care for childhood cancer survivors: a systematic review. Crit Rev Oncol Hematol. 2017 Jun;114:131-8. http://dx.doi.org/10.1016/j. critrevonc.2017.04.007 PMID:28477741

19. Lethaby CD, Picton S, Kinsey SE, Phillips R, van Laar M, Feltbower RG. A systematic review of time to diagnosis in children and young adults with cancer. Arch Dis Child. 2013 May;98(5):349-55. http://dx.doi.org/10.1136/archdischild-2012-303034 PMID:23476000

20. Neal RD, Tharmanathan P, France B, Din NU, Cotton S, Fallon-Ferguson J, et al. Is increased time to diagnosis and treatment in symptomatic cancer associated with poorer outcomes? Systematic review. Br J Cancer. 2015 Mar 31;112 Suppl 1:S92-107. http:// dx.doi.org/10.1038/bjc.2015.48 PMID:25734382

21. Furutani E, Rodriguez-Galindo C, Green AL. Early death in pediatric cancer: remaining questions and next steps. Oncotarget. 2017 Nov 1;8(57):96478-9. http://dx.doi.org/10.18632/oncotarget.22257 PMID:29228545 